\title{
ПРИМЕНЕНИЕ МЕТОДА ПРИВЕДЕННЫХ МОМЕНТОВ ДЛЯ РАСЧЕТА И ПОСТРОЕНИЯ СТАТИЧЕСКИХ ХАРАКТЕРИСТИК ТЕХНОЛОГИЧЕСКИХ УСТАНОВОК ГОРНОГО ПРОИЗВОДСТВА
}

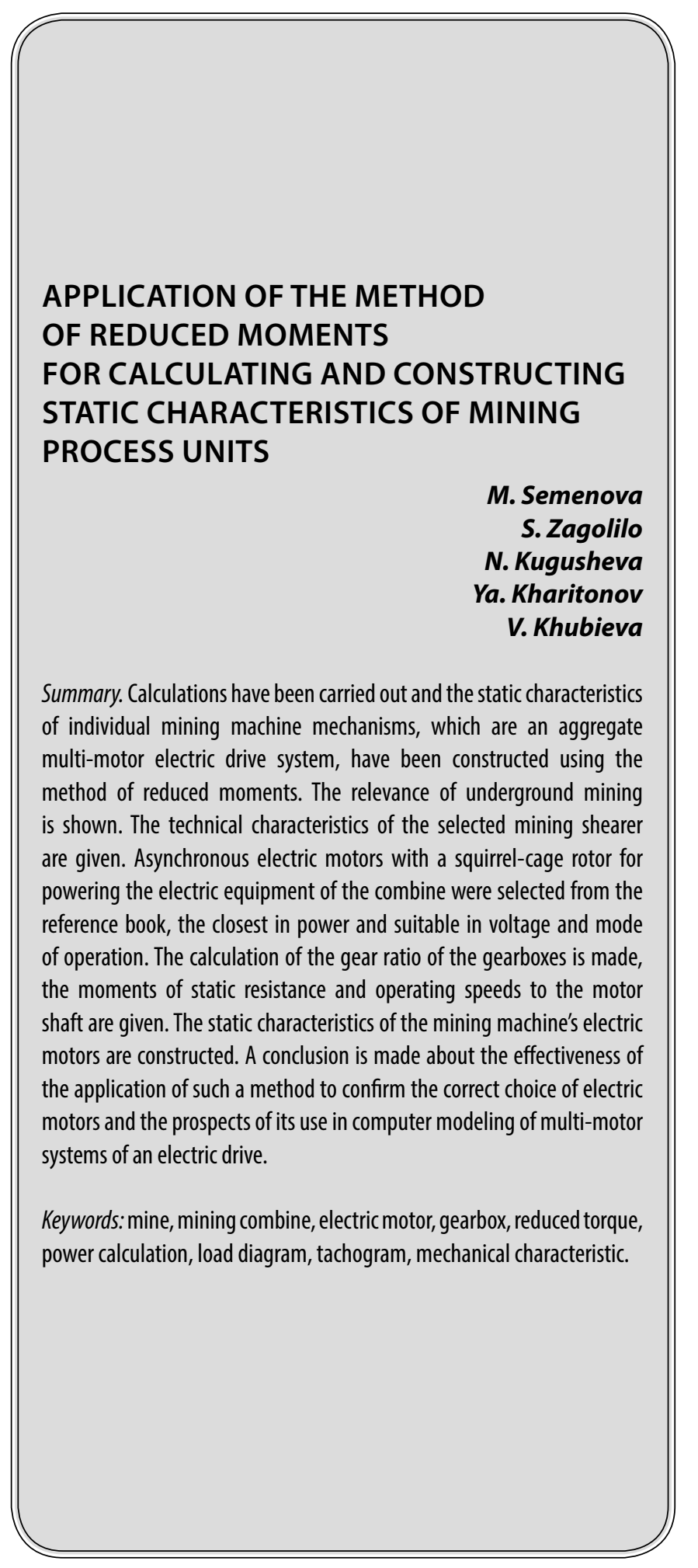

\author{
Семёнова Мария Николаевна \\ Старший преподаватель, Политехнический \\ институт (филиал) СВФУ им. М. К. Аммосова в г. Мирном \\ mariya_semyonova86@mail.ru \\ Заголило Сергей Анатольевич \\ Инженер, Политехнический институт (филиал) \\ СВФУ им. М. К. Аммосова в г. Мирном \\ exside93@mail.ru \\ Кугушева Наталья Николаевна \\ Старший преподаватель, Политехнический \\ институт (филиал) СВФУ им. М. К. Аммосова в г. Мирном \\ natali_k-80@mail.ru \\ Харитонов яков Станиславович \\ Аспирант, старший преподаватель, \\ Политехнический институт (филиал) СВФУ \\ им. М. К. Аммосова в г. Мирном \\ kharitonovyakov@gmail.com \\ Хубиева Виктория Махмутовна \\ Старший преподаватель, Политехнический \\ институт (филиал) СВФУ им. М. К. Аммосова в г. Мирном \\ lilacrose@mail.ru
}

Аннотация. Выполнены расчеты и произведено построение статических характеристик отдельных механизмов добычного комбайна, представляющих собой совокупную многодвигательную систему электропривода, методом приведенных моментов. Показана актуальность ведения добычных работ подземным способом. Приведены технические характеристики выбранного добычного комбайна. Из справочника выбраны ближайшие по мощности и подходящие по напряжению и режиму работы асинхронные электродвигатели с короткозамкнутым ротором для питания электрооборудования комбайна. Произведен расчет передаточного числа редукторов, приведены моменты статического сопротивления и рабочие скорости к валу двигателя. Построены статические характеристики электродвигателей добычного комбайна. Сделано заключение $0 б$ эффективности применения такой методики для подтверждения правильности выбора электродвигателей и перспективности её использования при компьютерном моделировании многодвигательных систем электропривода.

Ключевые слова: рудник, добычной комбайн, электродвигатель, редуктор, приведенный момент, расчет мощности, нагрузочная диаграмма, тахограмма, механическая характеристика. 


\section{Ввемение}

3 ападная Якутия, известная всему миру своими кимберлитовыми месторождениями (трубками) и предприятиями по добыче и переработке алмазосодержащего сырья, в настоящее время испытывает затруднения в связи с падением спроса на алмазо-бриллиантовую продукцию. В целях экономии были прекращены все открытые добычные работы (карьерный способ), и сейчас ведется разработка только подземным способом, а именно на трех рудниках «Интернациональный», «Айхал» и «Удачный» [1]. Обосновывается это экономической целесообразностью, т.к. снижаются затраты на вскрышные работы, требуется меньше специального карьерного транспорта.

Вопросы механизации погрузки разрушенной горной массы на забойный конвейер или другие транспортные средства имеют весьма важное значение как с точки зрения обеспечения высокопроизводительной работы выемочной машины, так и с точки зрения облегчения условий труда шахтеров, так как ручная погрузка горной массы - тяжелый физический труд, применяемый чаще всего в наиболее опасном, незакрепленном пространстве [2]. Основным направлением развития комплексной механизации проходческих и добычных работ в горной промышленности является внедрение комбайнового способа проведения выработок, уровень которого в 2018 году достиг 80\%. Используются в основном комбайны легкого и среднего типов (массой от 20 до 100 тонн и энерговооруженностью исполнительного органа от 100 до 300 кВт) [3].

Для проведения выработок по породам с коэффициентом крепости $f \geq 7$ (по шкале Протодьяконова) и площадью сечения $\mathrm{S} \leq 50 \mathrm{~m}^{2}$ серийно выпускаются средние и тяжелые добычные комбайны фирмы Voest-Alpine Bergtechnik GesmbH (австрийский производитель горнопроходческой техники) серии АМ, масса которых достигает 30-80 тонн с мощностью исполнительного органа 200-250 кВт. Добычные комбайны АМ представляют собой самоходную гусеничную машину с исполнительным органом стреловидного типа и погрузочным устройством в виде спаренных нагребающих лап на наклонном поворотном столе с самостоятельным приводом.

Актуальность, цель и задачи исследования. В связи со снижением объемов добычи на руднике «Интернациональный» начался этап отработки подкарьерных запасов через вспомогательный вентиляционный ствол, габариты которого не позволяют доставить к очистному забою добычной комбайн АМ-105, хорошо зарекомендовавший себя ранее на глубоких горизонтах. Для продолжения добычи на рудник был доставлен с рудника «Айхал» добычной комбайн АМ-75. Авторы заинтере- совались многодвигательной системой электропривода этого очистного комплекса и её энергетическими показателями. Поскольку рудник является объектом, опасным по газу и нефтепроявлениям, то просто “прийти" туда и измерить эти показатели не представляется возможным. Тогда было принято решение произвести необходимые расчеты и построить нужные диаграммы методом приведенных моментов.

Таким образом, целью настоящей работы станет расчет и построение статических характеристик многодвигательной системы электропривода добычного комбайна методом приведенных моментов. Для достижения поставленной цели будут решены следующие задачи: рассчитаны усилия работы механизмов на холостом ходу и под нагрузкой; определены интервалы времени работы и полный рабочий цикл; произведен предварительный выбор электродвигателей по рассчитанным параметрам; рассчитаны передаточные числа редукторов; приведены моменты статического сопротивления и рабочие скорости к валу двигателя; построены статические характеристики электродвигателей механизмов комбайна.

\section{Результаты исслеАования}

Расчет производительности и выбор комбайна. В качестве подтверждения обоснованности выбора добычного комбайна АМ-75 был произведен расчет производительности алмазодобывающего рудника, производительности и количества добычных комбайнов, темпов добычи с учетом падения спроса на алмазосодержащее сырье, который подробно представлен в [4]. Здесь покажем только таблицу составления основных параметров комбайна и его механизмов, необходимых для дальнейшего расчёта [5]. Исходными данными расчета являются физические и геометрические параметры, а также заданная производительность предприятия и комбайна (табл. 1).

Расчет и предварительный выбор электродвигателей. Для предварительного выбора электродвигателей необходимо построить нагрузочные диаграммы механизмов. Такие расчеты и методика построения нагрузочных диаграмм методом эквивалентных усилий подробно описаны в [4]. Здесь приведем лишь таблицу результатов расчета параметров механизмов комбайна, которые потребуются для дальнейших расчетов и построений статических характеристик (табл. 2).

Из таблицы видно, что наибольшее соотношение между рабочим усилием и усилием на холостом ходу наблюдается у самого мощного механизма - рабочего органа комбайна. Установочная мощность показывает минимально необходимую мощность электродвигателей 
Таблица 1. Технические характеристики комбайна АМ-75.

\begin{tabular}{|l|l|}
\hline Наименование параметра & 3начение \\
\hline Расчетная часовая производительность рудника, $A_{Y}$ & 136 т/час \\
\hline Часовая производительность комбайна, $Q_{\text {Kомь }}$ & 80 т/час \\
\hline Суммарная мощность электродвигателей комбайна, $\mathrm{P}_{\Sigma}$ & 350 кВт \\
\hline Мощность электродвигателя рабочего органа, $\mathrm{P}_{P O}$ & 200 кВт \\
\hline Мощность электродвигателей подборщика, $\mathrm{P}_{\Pi}$ & $2^{*} 36$ кВт \\
\hline Мощность электродвигателя конвейера, $\mathrm{P}_{K}$ & 70 кВт \\
\hline Режим работы основного электрооборудования & $\mathrm{S1}$ \\
\hline Диаметр зарубной головки рабочего органа, $D$ & 750 мм \\
\hline Ширина зарубного бара рабочего органа, $B$ & 1000 мм \\
\hline Длина стрелы рабочего органа, $L$ & 2500 мм \\
\hline Угол поворота и наклона стрелы, а & $30^{\circ}$ \\
\hline Масса комбайна, МКомБ & 52 тонны \\
\hline
\end{tabular}

Таблица 2. Результаты расчета параметров механизмов комбайна

\begin{tabular}{|c|c|c|c|}
\hline \multirow{2}{*}{ Параметр } & \multicolumn{3}{|c|}{ Механизм комбайна } \\
\hline & Рабочий орган & Подборщик & Конвейер \\
\hline Усилие на холостом ходу, $F_{X X}, \mathrm{H}$ & 7350 & 2312 & 3372 \\
\hline Рабочее усилие, $F_{P}, \mathrm{H}$ & 59780 & 5685 & 12704 \\
\hline Эквивалентное усилие, $\mathrm{F}_{\ni к в}, \mathrm{H}$ & 54400 & 5209 & 11625 \\
\hline Время холостого хода, $t_{X X}$ мин & 4,6 & 4,6 & 4,6 \\
\hline Время работы, $t_{P}$, мин & 43,4 & 43,4 & 43,4 \\
\hline Время цикла, $\mathrm{t}_{L,}$ мин & 52,6 & 52,6 & 52,6 \\
\hline Предварительная мощность, N, Вт & 147800 & 29597 & 60549 \\
\hline Установочная мощность, N, кBт & 170 & 34 & 70 \\
\hline
\end{tabular}

Таблица 3. Результаты выбора электродвигателей механизмов комбайна

\begin{tabular}{|c|c|c|c|}
\hline \multirow{2}{*}{ Параметр } & \multicolumn{3}{|l|}{ Механизм } \\
\hline & Рабочий орган & Подборщик & Конвейер \\
\hline Марка электродвигателя & 4 АЗ315М4У3 & АИР200M4 & AИP250S4 \\
\hline Высота оси вращения вала, & $315 \mathrm{Mm}$ & $200 \mathrm{MM}$ & $250 \mathrm{Mm}$ \\
\hline Мощность, & $200 \mathrm{kBT}$ & $37 \mathrm{kBT}$ & $75 \mathrm{kBT}$ \\
\hline Синхронная частота вращения, & 1500 об/мин & 1500 об/мин & 1500 об/мин \\
\hline Номинальная частота вращения, & 1480 об/мин & 1470 об/мин & 1478 об/мин \\
\hline Номинальное скольжение, & $1,3 \%$ & $2 \%$ & $1,5 \%$ \\
\hline КПД, & 0,94 & 0,925 & 0,94 \\
\hline Коэффициент мощности, & 0,92 & 0,89 & 0,88 \\
\hline Номинальное напряжение, & $1140 \mathrm{~B}$ & $660 \mathrm{~B}$ & $660 \mathrm{~B}$ \\
\hline Отношение пускового тока к номинальному, & 6,0 & 7,5 & 7,5 \\
\hline Отношение пускового момента к номинальному, & 1,3 & 1,7 & 1,7 \\
\hline Отношение максимального момента к номинальному, & 2,2 & 2,7 & 2,5 \\
\hline Момент инерции, & $3,63 \mathrm{k} \Gamma \cdot \mathrm{M}^{2}$ & $0,28 \mathrm{~K} \Gamma \cdot \mathrm{M}^{2}$ & $0,89 \mathrm{~K} \Gamma \cdot \mathrm{M}^{2}$ \\
\hline Число пар полюсов, & 2 & 2 & 2 \\
\hline
\end{tabular}


Таблица 4. Результаты расчета обмоточных данных электродвигателей

\begin{tabular}{|c|c|c|c|}
\hline \multirow{2}{*}{ Параметр } & \multicolumn{3}{|l|}{ Механизм } \\
\hline & Рабочий орган & Подборщик & Конвейер \\
\hline Марка электродвигателя & $4 \mathrm{~A} 315 \mathrm{M} 4 \mathrm{Y} 3$ & AИP200M4 & AИP250S4 \\
\hline Угловая скорость вращения, & 154,9 рад/с & 153,86 рад/с & 154,7 рад/с \\
\hline Номинальный ток, & $111,6 \mathrm{~A}$ & $38,7 \mathrm{~A}$ & $80,4 \mathrm{~A}$ \\
\hline Сопротивление статора, & 0,216 OM & 0,533 Ом & $0,174 \mathrm{OM}$ \\
\hline Сопротивление ротора, & $0,073 \mathrm{OM}$ & $0,176 \mathrm{OM}$ & $0,06 \mathrm{OM}$ \\
\hline Индуктивность обмоток, & $0,001 \Gamma \mathrm{H}$ & $0,001 \Gamma \mathrm{H}$ & $0,0008 \Gamma \mathrm{H}$ \\
\hline Взаимоиндукция, & 0,079 ГH & $0,119 Г \mathrm{H}$ & 0,0492 ГH \\
\hline Момент инерции, & $3,63 \mathrm{~K} \Gamma \cdot \mathrm{M}^{2}$ & $0,28 \mathrm{~K} \Gamma \cdot \mathrm{M}^{2}$ & $0,89 \mathrm{~K} \Gamma \cdot \mathrm{M}^{2}$ \\
\hline
\end{tabular}

механизмов для создания требуемых усилий при работе. Исходя из расчета, построенных нагрузочных диаграмм и приведенных кинематических схем в [4], выбираем из справочника ближайшие по мощности и подходящие по напряжению и режиму работы асинхронные электродвигатели с короткозамкнутым ротором (табл. 3).

Для последующих расчетов определим недостающие обмоточные данные электродвигателей. Методика такого расчета подробно описана в [6]. Здесь лишь покажем результаты расчета обмоточных данных (табл. 4).

Расчет и построение статических характеристик методом приведенных моментов. Для построения нагрузочной диаграммы и тахограммы электродвигателей произведем расчет передаточного числа редуктора, приведение моментов статического сопротивления и рабочих скоростей к валу двигателя, примем динамический момент и ускорение электропривода с учетом перегрузочной способности двигателя.

Определяем номинальный, пусковой и максимальный моменты электродвигателя по следующим формулам:

$$
M_{\mathrm{H}}=\frac{P_{\mathrm{H}}}{\omega_{\mathrm{H}}}, M_{\Pi}=k_{\Pi} \cdot M_{\mathrm{H}}, M_{\mathrm{M}}=k_{\mathrm{M}} \cdot M_{\mathrm{H}}[\mathrm{H} \cdot \mathrm{M}]
$$

где $K_{\Pi}=M_{\Pi} / M_{H}$ и $k_{M}=M_{M} / M_{N}$ - отношение пускового и максимального моментов к номинальному (принимаются по паспортным данным).

Передаточное число редуктора для каждого механизма определяется по формуле:

$$
i_{\mathrm{P}}=\frac{\omega_{\mathrm{H}}}{V_{\mathrm{M}} \cdot \pi} \cdot \frac{d}{2}
$$

где $\omega_{H}$ - номинальная скорость вращения двигателя, рад/с, $V_{M}$ - скорость движения (вращения) рассматриваемого механизма, м/c, $d$ - диаметр механизма вращения, м.
Моменты статического сопротивления, приведенные к валу двигателя, при рабочем усилии и на холостом ходу соответственно будут определяться как:

$$
M_{\mathrm{CP}, \mathrm{CXX}}=\frac{F_{\mathrm{P}, \mathrm{XX}} \cdot d / 2}{i_{\mathrm{P}} \cdot \eta}+M_{\mathrm{H}}[\mathrm{H} \cdot \mathrm{M}]
$$

где $\eta-$ КПД двигателя, $F_{p, X X}-$ усилия рабочее и на холостом ходу соответственно, которые определяются по выражениям:

$$
F_{\mathrm{P}}=\left(m_{\mathrm{M}}+m_{\Gamma}\right) \cdot g \cdot \rho \cdot \mu, F_{\mathrm{XX}}=m_{\mathrm{M}} \cdot g \cdot \mu[\mathrm{H}]
$$

где $m_{M}$ и $m_{\Gamma}-$ собственная масса механизма и масса груза соответственно, кг, $\mu-$ коэффициент трения, $\rho-$ коэффициент плотности (для сыпучих грузов), кг/м³.

Суммарный момент инерции привода определяется по формуле:

$$
J_{\mathrm{y}}=\text { д } \cdot J+m_{\mathrm{M}} \cdot \frac{d^{2} / 2}{i_{p}}\left[\kappa \Gamma \cdot \mathrm{M}^{2}\right]
$$

где $J$ - момент инерции двигателя, кг·м² ${ }^{2}$ д = 1,2/1,5коэффициент, учитывающий момент инерции муфт и редуктора.

Определяем динамический момент двигателя по условию максимального использования двигателя по перегрузочной способности:

$$
M_{\text {Дин }}=k_{\Pi \text { П }} \cdot\left(M_{\mathrm{M}}-M_{\mathrm{CP}}\right)[\mathrm{H} \cdot \mathrm{M}]
$$

где $k_{П Р}-$ коэффициент, учитывающий перерегулирование момента на уточненной нагрузочной диаграмме.

Ускорение вала двигателя и рабочего органа механизма в переходных режимах найдем соответственно по формулам:

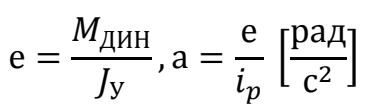




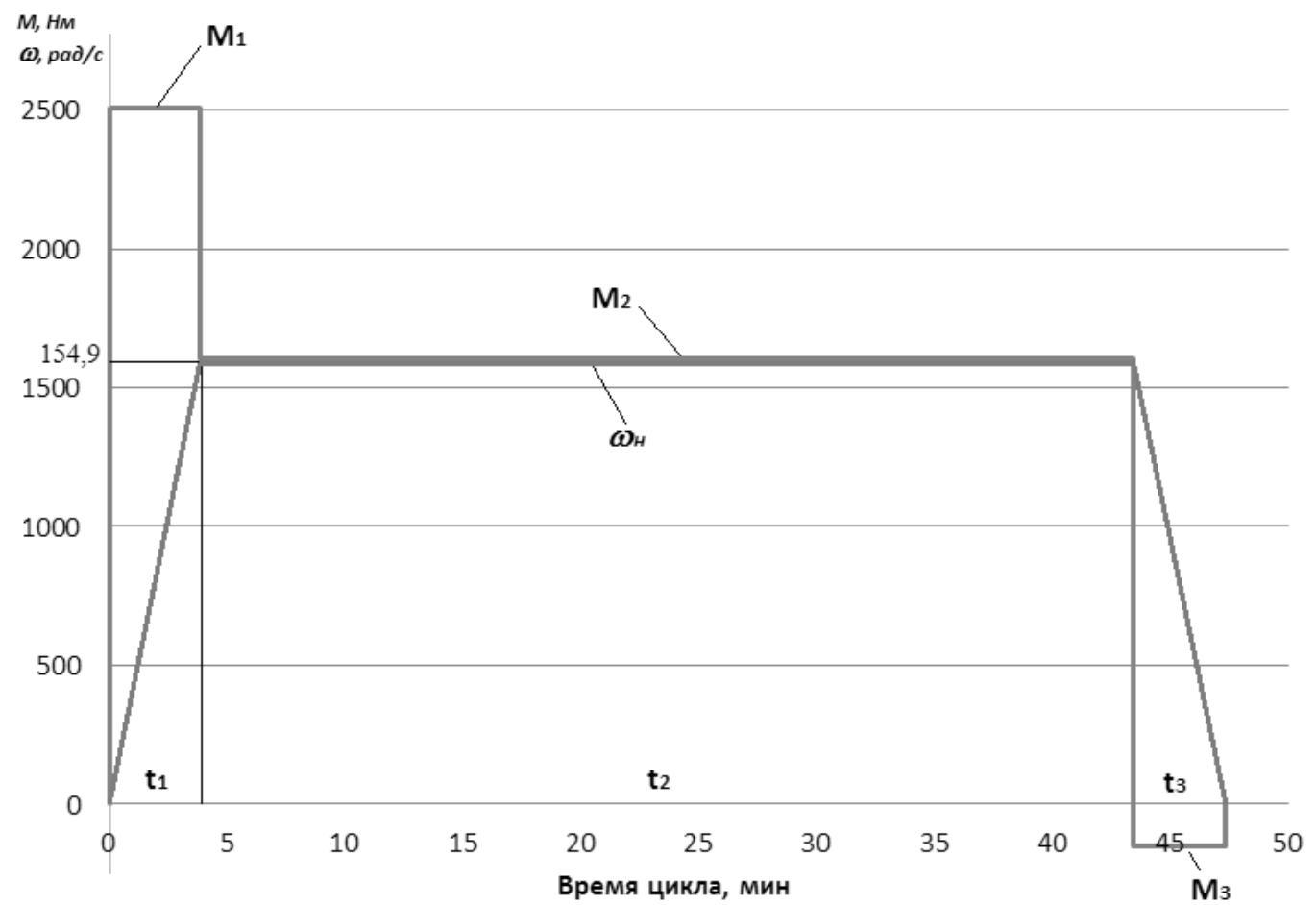

Рис. 1. Нагрузочная диаграмма и тахограмма электродвигателя рабочего органа добычного комбайна

Для построения нагрузочной диаграммы разбиваем её на 3 интервала. Сначала рассчитываем интервалы разгона и замедления электропривода, затем интервал работы с постоянной скоростью. Определим время разгона и замедления (1 и 3 интервалы), а также величины моментов в эти интервалы, по следующим формулам:

$$
\begin{aligned}
& t_{1}=t_{3}=\frac{щ_{\mathrm{H}}}{\mathrm{e}}[\mathrm{c}], M_{1}=M_{\text {дин }}+M_{\mathrm{CXX}}, M_{3}= \\
& =M_{\text {дин }}-M_{\mathrm{CXX}}[\mathrm{H} \cdot \mathrm{M}]
\end{aligned}
$$

Продолжительность работы электродвигателей с постоянной скоростью будет зависеть от типа механизма, его режима работы и технологических условий. В нашем случае для добычного комбайна технологический процесс заключается в отработке очистного пространства, поэтому время работы будет определяться как:

$$
t_{2}=\frac{S_{\mathrm{B}} \cdot Q_{\mathrm{M}} \cdot \mathrm{c} \cdot 1000}{V_{\mathrm{M}} \cdot m_{\mathrm{M}} \cdot 60}[\text { мин }]
$$

где $S_{B}$ - площадь выработки, м², $Q_{M}-$ производительность механизма, $\mathrm{M}^{3} /$ мин.

$$
M_{2}=M_{\mathrm{CP}}[\mathrm{H} \cdot \mathrm{M}] .
$$

Момент двигателя во время работы с постоянной скорость равен моменту статического сопротивления при рабочем усилии, в нашем случае:.
Произведем расчет и построение нагрузочной диаграммы и тахограммы для самого мощного электродвигателя добычного комбайна - стреловидного рабочего органа. Применим пакет Mathcad для осуществления расчетов и приложение MS Office/Excel для построения диаграммы. Результат расчета и построения нагрузочной диаграммы и тахограммы представлен на рис. 1.

Теперь произведем расчет и построим механическую характеристику электродвигателя, которая определяется как зависимость угловой скорости вращения от электромагнитного момента двигателя $M$, т.е. получим функцию $f=u(M)$. Для этого воспользуемся формулой Клосса, задавшись значениями скольжения от 0 до 1 (включая номинальное и критическое значение) и подставив в выражение:

$$
M=2 \cdot M_{\mathrm{M}} \cdot \frac{1+a \cdot s_{\mathrm{KP}}}{\frac{s}{s_{\mathrm{KP}}}+\frac{s_{\mathrm{KP}}}{S}+2 \cdot a \cdot s_{\mathrm{KP}}}[\mathrm{H} \cdot \mathrm{M}]
$$

где.

$$
a=R_{s} /\left(R_{r} \cdot k^{2}\right) .
$$

Аналогично, как и для нагрузочной диаграммы, произведем расчет и построим механическую характеристику для электродвигателя рабочего органа комбайна, воспользовавшись теми же программами Mathcad и MS 


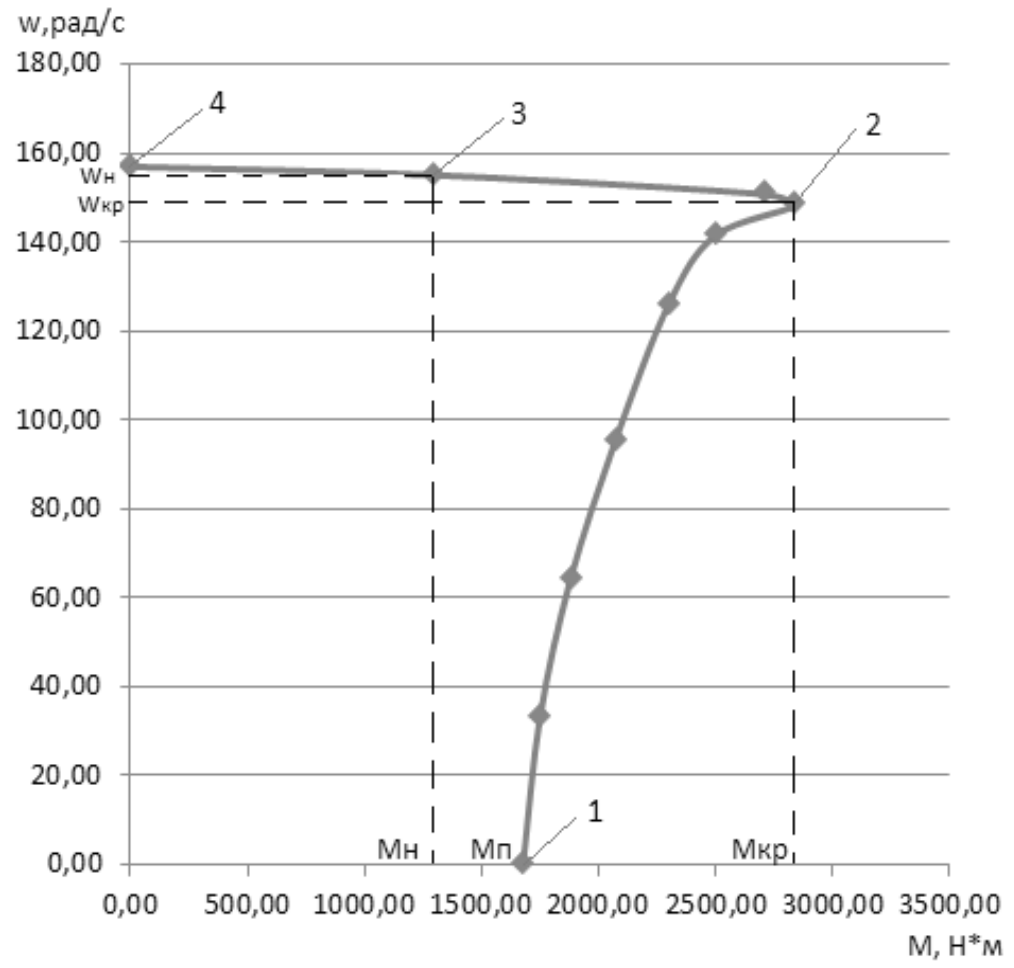

Рис. 2. Механическая характеристика электродвигателя рабочего органа добычного комбайна

Office/Excel. Полученную механическую характеристику можно увидеть на рис. 2.

На последнем графике имеются четыре точки, характерные для асинхронного электродвигателя: 1 - момент пуска двигателя (скорость равна нулю, момент принимает пусковое значение), 2 - критический режим работы (момент имеет максимальное значение, превышение которого не позволит произвести запуск двигателя), 3 номинальный режим работы (скорость и момент имеют номинальные значения), 4 - точка идеального холостого хода (момент двигателя равен нулю, скорость вращения ротора равна скорости вращения магнитного поля статора). Поскольку точка рабочего момента не превышает значения пускового и критического моментов, можно считать, что предварительный выбор электродвигателей произведен корректно.

Заключение. В результате выполненных расчетов были построены статические характеристики многодви- гательной системы электропривода добычного комбайна методом приведенных моментов. Такие исследования актуальны для алмазодобывающей промышленности Западной Якутии. По рассчитанным ранее эквивалентным усилиям была определена предварительная и установочная мощности электродвигателей механизмов комбайна. По рассчитанным приведенным моментам были построены статические характеристики предварительно выбранных электродвигателей. Характеристики подтверждают корректность выбранных ранее электродвигателей. Выполненные расчеты будут полезны для дальнейшего компьютерного моделирования работы систем электропривода добычного комбайна и системы электроснабжения добычного участка [7-11]. В нашем случае компьютерное моделирование является единственно возможным инструментом для дальнейшей оценки качества электрической энергии в подземной части рудника, куда нет возможности попасть для проведения экспериментальных исследований и физических измерений [12-16].

\section{ЛИТЕРАТУРА}

1. Чаадаев А.С., Зырянов И. В., Кириллов Д.С., Бондаренко И. Ф. Создание и промышленное внедрение систем подземной разработки алмазных месторождений АК «АЛРОСА» (ПАО) // Горный журнал.— 2015.— № 11.—C. 48-52. D0I: 10.17580/gzh.2015.11.10

2. Махно Д.Е. К вопросу совершенствования средств комплексной механизации на угольных шахтах // Горное оборудование и электромеханика.-2013.№ 10.- - C. 2-6. 
3. Махно Д.Е., Федорко В. П. Проблемы комплексной механизации очистных работ на угольных шахтах // Вестник Иркутского государственного технического университета.— 2012.—№ 12 (71).-С. 110-113.

4. Заголило С.А., Семёнов А.С. Расчет и выбор электродвигателей механизмов добычного комбайна методом эквивалентных усилий // Международный журнал прикладных и фундаментальных исследований._ 2020.— № 2.—C. 104-109. DOI: 10.17513/mjpfi.13019

5. Инструкция по эксплуатации AM 75/162. VOEST-ALPINE Bergtechnik Ges.m.b.H. A-8740 Zeltweg, AUSTRIA. 01-09-05.

6. Заголило С.А., Семёнов А.С., Семёнова М. Н., Якушев И. А. Компьютерное моделирование многодвигательной системы электропривода в пакете программ MatLab // Моделирование, оптимизация и информационные технологии. — 2020.— T. 8. — № 2. URL: https://moit.vivt.ru/wp-content/uploads/2020/05/ ZagoliloSoavtors_2_20_1.pdf (дата обращения: 18.08.2020). DOl: 10.26102/2310-6018/2020.29.2.012

7. Семёнов А.С., Егоров А.Н. Особенности математического моделирования систем электроприводов технологических установок горных предприятий // Каротажник. - 2018. — № 11 (293).- - С. 85-99.

8. Семёнов А.С., Харитонов Я.С., Егоров А. Н. Разработка математической модели электромагнитного привода с системой управления стабилизации производительности питателя // Труды НГтУ им. Р. Е. Алексеева.— 2018. — № 2 (121).—C. 123-131.

9. Бебихов Ю.В., Кугушева Н. Н., Хубиева В. М., Семёнова М. Н., Якушев И. А. Разработка универсальной математической модели системы электроснабжения участка промышленного предприятия // Естественные и технические науки.—2018. — № 12 (126).—C. 387-394.

10. Семёнов А.С., Якушев И. А., Егоров А. Н. Математическое моделирование технических систем в среде MATLAB // Современные наукоемкие технологии.2017.— № 8.-C. 56-64. D0I: 10.17513/snt.36780

11. Бебихов Ю.В., Семёнов А. С., Семёнова М. Н., Якушев И. А. Анализ методов моделирования технических систем в среде МАTLAB // Моделирование, оптимизация и информационные технологии.— 2019.—- T. 7.— № 3 (26). URL: https://moit.vivt.ru/wp-content/uploads/2019/09/BebihovSoavtori_3_19_1.pdf (дата обращения: 18.08.2020). DOI: 10.26102/2310-6018/2019.26.3.037

12. Кузнецов Н.М., Семёнов А.С., Бебихов Ю. В., Рыбников А. В. Результаты мониторинга показателей качества электрической энергии потребителей подземного рудника // Горный журнал.— 2014.— № 1.- С. 23-26.

13. Семёнов А.С., Кузнецов Н. М. Анализ результатов мониторинга показателей качества электрической энергии в подземном руднике // Измерительная техника. - 2014.- № 4.- - . 31-34.

14. Egorov A.N., Semenov A.S., Bebikhov Yu.V., Sigaenko A. A. Assessment of the Energy Efficient of the Modernized Main Fan Unit of the Underground Mine // International Journal of Energy for a Clean Environment. — 2019.— V. 20. — № 2.—P. 153-165. D0I: 10.1615/InterJEnerCleanEnv.2019026505

15. Егоров А.Н., Семенов А. С., Харитонов Я.С., Федоров О. В. Анализ эффективности применения частотно-регулируемого электропривода в условиях алмазодобывающих предприятий // Горный журнал.— 2019.— № 2.—C. 77-82. D0I: 10.17580/gzh.2019.02.16

16. Егоров А.Н.,Харитонов Я.С.,Шевчук В. А.,Семенов А. С. Влияниевысшихгармоникнаработупреобразователячастоты вусловияхподземногорудника//Известия Томского политехнического университета. Инжиниринг георесурсов.—2020.—T.331.— № 6.—C. 141-151. D0I: 10.18799/24131830/2020/6/2683

\footnotetext{
○ Семёнова Мария Николаевна ( mariya_semyonova86@mail.ru ), Заголило Сергей Анатольевич ( exside93@mail.ru ),

Кугушева Наталья Николаевна ( natali_k-80@mail.ru ), Харитонов Яков Станиславович ( kharitonovyakov@gmail.com ),

Хубиева Виктория Махмутовна ( lilacrose@mail.ru).

Журнал «Современная наука: актуальные проблемы теории и практики»
} 